\title{
Isolation and Properties of Spore Germination Mutants of Bacillus subtilis 168 Deficient in the Initiation of Germination
}

\author{
By R. L. SAMMONS, $†$ A. MOIR AND D. A. SMITH* \\ Department of Genetics, University of Birmingham, P.O. Box 363, Birmingham B15 2TT
}

(Received 3 October 1980)

\begin{abstract}
Two spore germination mutants of Bacillus subtilis 168 (GerA38 and GerA44) deficient at a very early stage of germination prior to loss of heat resistance and absorbance were isolated. In contrast to the wild-type their spores required higher concentrations of germinant and had a slower germination rate and longer average microlag in $\mathrm{L}$-alanine, $\mathrm{L}$ - $\alpha$-aminobutyrate, DL- $\beta$-aminobutyrate and L-valine. Although wild-type spores germinated in $0.1 \mathrm{M}$-cycloleucine the mutants did not, but did so normally in L-asparagine plus glucose, fructose and $\mathrm{KCl}$. GerA44 was more defective than GerA38. Their germination abnormalities were partially corrected if glucose, fructose and $\mathrm{KCl}$ were added to $\mathrm{L}$-alanine or $\mathrm{L}$-valine. Germination of both mutants in L-alanine was more sensitive than the wild-type to inhibition by D-alanine, the sensitivity of GerA44 being greater than that of GerA38. Two other GerA mutants which did not germinate in L-alanine, even at high concentrations, were able to use it as a source of carbon or nitrogen at rates equal to those of the wild-type. A similar mutant and GerA44 show normal chemotaxis to L-alanine. Thus, the deficiencies of GerA mutants appear to be spore specific. GerA 38 and gerA 44 mutations were approximately $75 \%$ and $43 \%$ cotransduced with cysB and thr-5, respectively, with phage PBS1. They mapped within a cluster of gerA mutations that were $70-90 \%$ cotransduced with citG4 by phage SPP1. Although other GerA mutants cannot germinate in $\mathrm{L}$-alanine plus $\mathrm{KCl}$ no difference in map location between their mutations and gerA 38 and gerA 44 could be detected.
\end{abstract}

\section{INTRODUCTION}

During germination, bacterial spores undergo a series of biochemical and physiological changes which result in the loss of resistance to heat, chemical and mechanical injury, radiation and desiccation. These changes are accompanied by loss of absorbance and ultimately reacquisition of a level of metabolic activity equal to that of a vegetative cell (Gould, 1969). In Bacillus subtilis 168 these events may follow contact of the spore with a single specific amino acid, such as L-alanine, alone or in combination with salts and sugars, such as $\mathrm{KCl}$, glucose and fructose (Prasad et al., 1972; Moir et al., 1979). The mechanism by which such chemicals initiate germination is not known. Prasad et al. (1972) suggested that spores of $B$. subtilis 168 require for germination fructose 6-phosphate, NADH and an undefined aminated derivative, all of which could be supplied by metabolism of L-alanine. However, similar metabolism of other germinative amino acids, such as L-valine and L- $\alpha$ - and $\beta$-aminobutyrate, may not be possible since the spore may not possess the necessary enzymes. For example, fumarase is necessary in the pathway of conversion of L-valine to pyruvate but this enzyme has not been detected in spores of $B$. subtilis 168 (Goldman \& Blumenthal, 1964). 'Non-metabolizable' germinative amino acids may trigger the breakdown of an endogenous substrate as suggested by Freese et al. (1964). Studies with Bacillus megaterium QMB1551 and KM (Rossignol \& Vary, 1979; Scott \& Ellar, 1978 a,b) indicate

† Present address: Centre de Génétique Moléculaire, Centre National de la Recherche Scientifique, 91190 Gif-sur-Yvette, France. 
that little if any metabolism of the germinant or an endogenous substrate is required prior to loss of absorbance by germinating spores. Thus, initiation of germination may take place by a purely biophysical mechanism.

To investigate the initiation of germination of spores of $B$. subtilis 168 we have isolated mutants blocked at a very early stage of germination, prior to loss of heat resistance and absorbance. L-Valine was used as the germinant in an enrichment procedure since spores specifically unable to germinate in it should be blocked prior to the breakdown of an endogenous substrate, perhaps in the primary triggering event(s) itself. The germination properties of these mutants and those of the wild-type strain support the view that metabolism of the germinant is not required for initiation of germination. These studies also suggest that $\mathrm{L}$-alanine and structurally related amino acids are involved in a common step in germination different from that in which asparagine is involved. A preliminary account of some of this work was given by Smith et al. (1978).

\section{METHODS}

Bacteria and phage. All bacteria were derivatives of B. subtilis 168 . Mutants GerA86 and GerA97 were described by Trowsdale \& Smith (1975) and all other Ger mutants (except GerA38 and GerA44) and strains BD111, BD92 and JH404 by Moir et al. (1979). The wild-type strain from which both GerA38 and GerA44 were isolated was strain 1604 (Moir et al., 1979). Mutant GerA44 was derived from cultures irradiated with ultraviolet light and enriched for mutants unable to germinate in Penassay broth (Moir et al., 1979). Strains MB54 and BD34 and the nonsense suppressible derivative sus-5 of phage SPO-1 were obtained from Dr P. Piggot.

Media, and preparation of spore suspensions. These were as previously described (Lafferty \& Moir, 1977; Moir et al., 1979).

Isolation of mutant GerA38. Cultures were treated with $N$-methyl- $N^{\prime}$-nitro- $N$-nitrosoguanidine, as described by Moir $e$ t al. (1979) and allowed to sporulate. The spores were harvested and washed and a suspension was prepared containing approximately $10^{7}$ spores $\mathrm{ml}^{-1}$ in $0.1 \mathrm{M}$-Tris/ $\mathrm{HCl} \mathrm{pH} 7.4$ plus $0.01 \mathrm{M}$-L-valine. This was incubated at $25^{\circ} \mathrm{C}$ with shaking for $90 \mathrm{~min}$ and then germinated spores were killed by heating at $80^{\circ} \mathrm{C}$ for $10 \mathrm{~min}$. This procedure was repeated after two further $90 \mathrm{~min}$ periods at $25^{\circ} \mathrm{C}$ and finally after $16-18 \mathrm{~h}$ incubation. Survivors were resuspended in $0.1 \mathrm{M}$-Tris/ $\mathrm{HCl} \mathrm{pH} 7.4$ plus $0.01 \mathrm{M}$-L-alanine and incubated for $2 \mathrm{~h}$ at $25^{\circ} \mathrm{C}$ to permit germination. Germinated spores were spread on potato glucose yeast extract agar (PGYEA) and incubated at $25^{\circ} \mathrm{C}$ for $18 \mathrm{~h}$ to obtain single colonies. Some bacteria from each colony were transferred to PGYEA to obtain sporulating colonies to test their colour reaction by the tetrazolium overlay method (Moir et al., 1979). Spores were prepared from tetrazolium white $\left(\mathrm{Ger}^{-}\right)$and $\mathrm{red}\left(\mathrm{Ger}^{+}\right.$, wild-type) colonies and their germination was compared by monitoring loss of absorbance in both $0.01 \mathrm{M}$-L-alanine and L-valine. GerA38 was chosen for further study since it germinated only in the former. It was derived from a culture mutagenized by Dr E. Lafferty.

Germination studies. Unless otherwise stated all measurements of germination were carried out at $37^{\circ} \mathrm{C}$ in $0.01 \mathrm{M}-\mathrm{Tris} / \mathrm{HCl} \mathrm{pH} \mathrm{8.4}$. This concentration and $\mathrm{pH}$ of Tris/ $\mathrm{HCl}$ are optimal for germination of wild-type spores (Sammons, 1980). Measurement of germination by loss of absorbance at $580 \mathrm{~nm}$ of a spore suspension was as previously described (Moir et al., 1979). To measure loss of heat resistance, $0.1 \mathrm{ml}$ samples were taken immediately after measurement of absorbance, transferred to $10 \mathrm{ml}$ distilled water at $70^{\circ} \mathrm{C}$, incubated for $30 \mathrm{~min}$ and then cooled in ice; $1 \mathrm{ml}$ samples of appropriate dilutions in distilled water were mixed in Petri dishes with $15 \mathrm{ml}$ PGYEA at $56^{\circ} \mathrm{C}$, and the plates were incubated at $37^{\circ} \mathrm{C}$ for $16-18 \mathrm{~h}$ to obtain viable counts from which the numbers of heat-resistant spores in the original samples were calculated. The number of survivors from samples taken immediately after the addition of germinant $\left(t_{0}\right)$ was taken as the original number of dormant spores in the population. The percentage loss of heat resistance at time $t_{\mathrm{t}}$ after the addition of germinant was calculated as $100 \times\left\{1-\left[\left(\right.\right.\right.$ No. of survivors at $\left.t_{\mathrm{t}}\right) /\left(\right.$ No. of survivors at $\left.\left.\left.t_{0}\right)\right]\right\}$.

To follow germination in L-alanine or $\mathrm{L}$-valine plus glucose, fructose and $\mathrm{KCl}$, spores that had been heat-activated at $70^{\circ} \mathrm{C}$ for $30 \mathrm{~min}$ were suspended in Tris/ $\mathrm{HCl}$ containing glucose, fructose and $\mathrm{KCl}$ and equilibrated at $37^{\circ} \mathrm{C}$ for $15 \mathrm{~min}$ prior to initiation of germination by addition of the amino acid. Final concentrations were $0.01 \mathrm{M}$-glucose and fructose and $0.03 \mathrm{M}-\mathrm{KCl}$.

Inhibition of germination by $\mathbf{D}$-alanine was determined using solutions of $\mathbf{L}$ - and $\mathbf{D}$-alanine made up at 20 times the final concentration in Tris/ $\mathrm{HCl}$ and mixed in equal volumes to give different ratios of $\mathrm{L}$-alanine to $\mathrm{D}$-alanine. Germination was initiated by 10 -fold dilution of each mixture into a suspension of spores at $37^{\circ} \mathrm{C}$ and monitored by loss of absorbance.

All amino acids used as germinants were purchased from Sigma except $L-\alpha$-aminobutyrate (Calbiochem). L-Alanine, D-alanine and L-valine contained less than $0.1 \%$ of any other amino acid (J. E. Fox, Macromolecular 
Analysis Service, University of Birmingham) as did cycloleucine (Sigma, personal communication). $O$ Carbamyl-D-serine was a gift from D. Hidy, International Minerals and Chemical Corporation, Terre Haute, Ind., U.S.A.

Mapping. Transduction by phage PBS1 was carried out as described by Moir et al. (1979) and transduction by phage SPP1 by the method of Ferrari et al. (1978). To increase the number of transductants in crosses involving strain JH404 (citG4 trpC2), phage lysates were irradiated for 1 min using a Hanovia low-pressure ultraviolet lamp with the bulb $20 \mathrm{~cm}$ from $1.4 \mathrm{ml}$ of the phage suspension in a glass Petri dish; this dose reduced by $99 \%$ the viability of a suspension of approximately $2 \times 10^{8} \mathrm{~B}$. subtilis 168 bacteria ml $\mathrm{ml}^{-1}$ in minimal salts medium irradiated in the same way. Germination-deficient $\left(\mathrm{Ger}^{-}\right)$colonies were identified by the tetrazolium overlay test. In cotransduction experiments the mean number of recombinants screened per cross was 120 (range 95-164).

Chemotaxis. The method of Adler (1973) was used.

Measurement of growth rates using L-alanine as a carbon or nitrogen source. Samples taken from an exponential phase culture of bacteria in Difco Penassay broth (PAB) were diluted 1/50 into minimal salts medium prepared without ammonium sulphate and supplemented with $20 \mu \mathrm{g} \mathrm{L}$-tryptophan $\mathrm{ml}^{-1}, 0.1 \mathrm{M}$-L-alanine and $0.5 \%$ $(\mathrm{w} / \mathrm{v})$ glucose (L-alanine as nitrogen source) or into minimal salts medium with $20 \mu \mathrm{g}$ tryptophan $\mathrm{ml}^{-1}$ and $0.1 \mathrm{M}$-L-alanine (carbon source), grown for $16-18 \mathrm{~h}$ at $37^{\circ} \mathrm{C}$ and then used to inoculate $50 \mathrm{ml}$ of the same medium in $250 \mathrm{ml}$ flasks to an $A_{600}$ of approximately $0 \cdot 1$. Incubation was continued on a Gallenkamp $1 \mathrm{H} 350$ reciprocal shaker at $37^{\circ} \mathrm{C}$ at 60 strokes $\mathrm{min}^{-1}$ and the $A_{600}$ of $1 \mathrm{ml}$ samples was measured at 30 min intervals for $3 \cdot 5-5 \cdot 5 \mathrm{~h}$.

Screening for gerA nonsense mutations. The nonsense suppressor mutation sup-3 (Georgopoulos, 1969) was transferred by PBS1 transduction into GerA strains carrying nonsense auxotrophic mutations. Its presence in prototrophic transductants was confirmed by plaque formation in cross-streaking tests on minimal agar (MA) by phage SPO-1 carrying the nonsense suppressible mutation sus-5.

Dipicolinic acid. This was released from spores by autoclaving, as described by Scott \& Ellar (1978c), and measured by their method or by that of Janssen et al. (1958).

\section{RESULTS}

\section{Effect of germinant concentration on the germination of wild-type and mutant spores}

Mutant GerA38 was isolated following mutagenesis and enrichment for mutants whose spores were unable to germinate specifically in L-valine and blocked prior to loss of heat resistance. Unlike spores of the wild-type its spores failed to germinate in $10^{-2} \mathrm{M}$-L-valine and $5 \times 10^{-4} \mathrm{M}$-L-alanine but did so at higher concentrations. Spores of GerA44 were found to possess similar properties.

To compare the germination of mutant and wild-type spores, three parameters $\left(C_{50}, G_{\max }\right.$ and AM) derived from curves showing the loss of absorbance of spore suspensions in a range of concentrations of germinant (e.g. Fig. $1 a$ ) were used. The maximum slope of each curve (germination rate) was plotted against germinant concentration on a logarithmic scale giving a curve from which $C_{50}$ and $G_{\max }$ values were obtained (Fig. $1 b$ ). $C_{50}$ is defined as the concentration of germinant required to achieve $50 \%$ of the maximum germination rate $\left(G_{\max }\right)$. The relationship between germination rate and germinant concentration for these spores does not obey Michaelis-Menten kinetics since plots of 1 /germination rate versus $1 /$ germinant concentration were non-linear. In the absence of a more precise measurement, the $C_{50}$ value was used to compare the relative effectiveness of particular germinants for mutant and wild-type spores. The concentration dependence of germination may reflect the affinity of spores for the germinant; thus, differences in $C_{50}$ may well reflect differences in germinant binding. The third parameter, average microlag (AM; Vary \& Halvorson, 1965), was determined under conditions in which $99 \%$ of the spores germinated in the minimum concentration of germinant required for the maximum germination rate (i.e. $C_{100}$; Fig. $1 \mathrm{c}$ ). $C_{50}$ values varied by approximately 2 -fold and $G_{\max }$ and $\mathrm{AM}$ by about 3 -fold between experiments performed on different occasions using different spore preparations. Therefore, wherever possible, comparisons were only made between $C_{50}, G_{\max }$ and $\mathrm{AM}$ values obtained in the same experiment and using spores prepared on the same occasion under identical conditions.

In order to quantify and determine the specificity of the germination deficiencies of GerA38 and GerA44, the $C_{50}, G_{\max }$ and $\mathrm{AM}$ values of wild-type and mutant spores were determined 

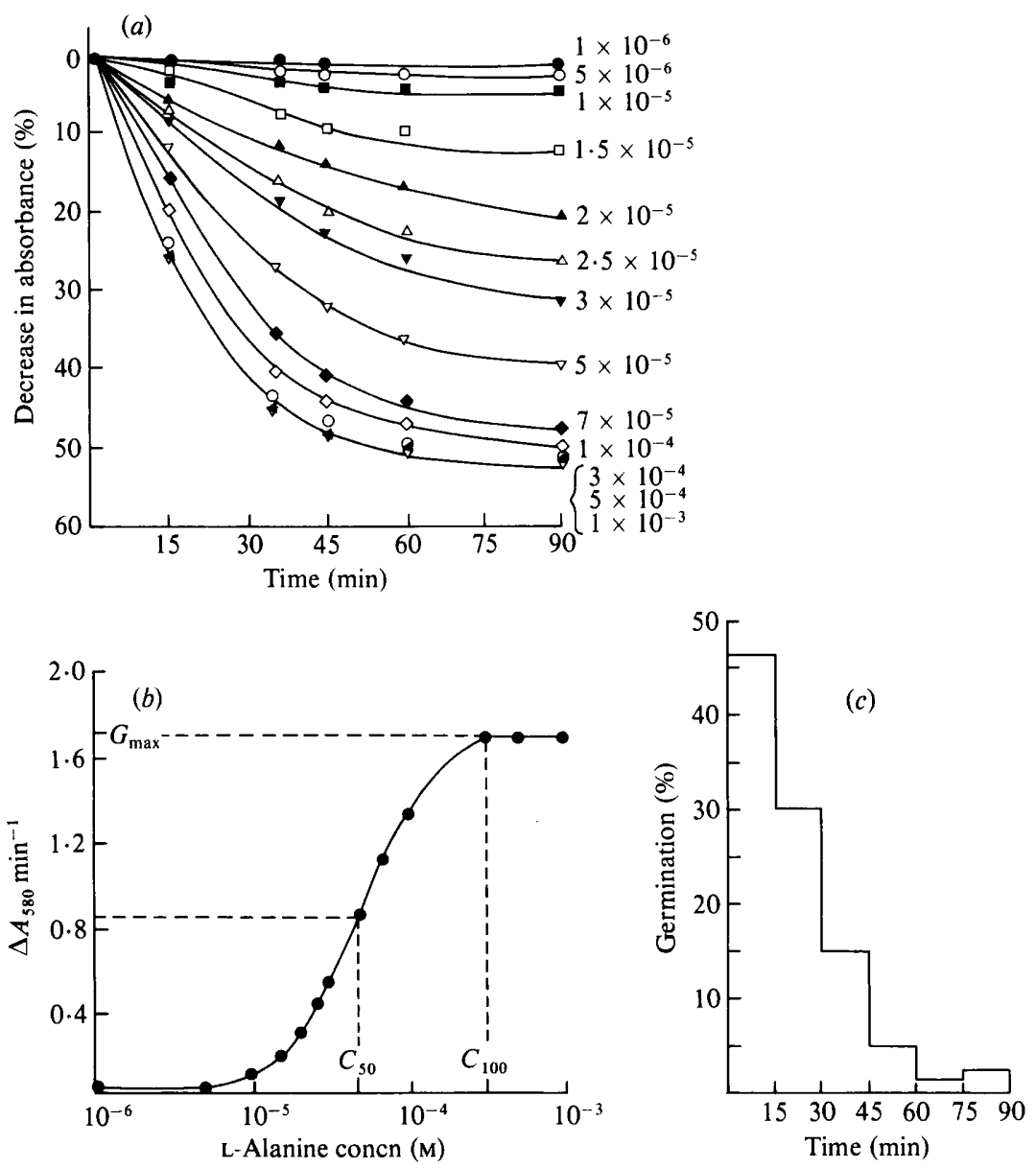

Fig. 1. Germination characteristics of wild-type spores responding to different concentrations of germinant. (a) Loss of absorbance of spores germinating in L-alanine at different concentrations (M, indicated on the figure). (b) Maximum slope of each curve $\left(\Delta A_{980} \min ^{-1}\right)$ plotted against alanine concentration ( $\log$ scale). $C_{100}$ is the minimum concentration of L-alanine required to obtain the maximum germination rate $\left(G_{\max }\right) ; C_{50}$ is the concentration required for $50 \%$ of $G_{\max }$. At $C_{100}(3 \times$ $10^{-4} \mathrm{M}$ ) the maximum loss of absorbance after $90 \mathrm{~min}$ represents germination of $99 \%$ of the spores as confirmed by phase contrast microscopy. (c) Percentage germination of total spore population in 15 min intervals after addition of germinant. The percentage losses of absorbance after 15, 30, 45, 60 and $75 \mathrm{~min}$ have been normalized to that after $90 \mathrm{~min}$ and plotted as a histogram. The arithmetic mean of this distribution is taken to be the average microlag, AM (min).

in L-alanine, $\mathrm{L}$ - $\alpha$-aminobutyrate, DL- $\beta$-aminobutyrate, L-valine and cycloleucine (Table 1 ). $\mathrm{L}$-Alanine and L-valine were tested in the same experiment and so comparisons between responses of wild-type and mutant spores in each of these amino acids are valid. Other amino acids were tested on different occasions. The efficiency of the amino acids as germinants decreased in the above order for both wild-type and mutant spores (cycloleucine was germinative only for the wild-type, even at $10^{-1} \mathrm{M}$ ). The mutants required higher concentrations of each amino acid for germination and tended to have lower $G_{\max }$ and longer AM values. GerA44 showed consistently higher $C_{50}$ values than did GerA38 and was also more defective with respect to $G_{\max }$ and AM. This suggested that the deficiencies of the mutants had simultaneously caused a change in germinant affinity, germination rate and average microlag. Differences between $C_{50}$ values for L-alanine were particularly clear, that of GerA38 being approximately 10-fold higher and GerA44 100-fold higher than that of the 
Table 1. Comparison of the germination of wild-type, GerA38 and GerA44 spores in different amino acids

$C_{50}$ is the concentration $(\mathrm{M})$ of germinant required to achieve $50 \%$ of the maximum germination rate $\left(G_{\max }, \Delta A_{580} \min ^{-1}\right) ; \mathrm{AM}$ is the average microlag $(\mathrm{min})$.

\begin{tabular}{|c|c|c|c|c|c|c|c|c|c|}
\hline \multirow[b]{2}{*}{ Germinant } & \multicolumn{3}{|c|}{ Wild-type } & \multicolumn{3}{|c|}{ GerA38 } & \multicolumn{3}{|c|}{ GerA44 } \\
\hline & $C_{50}$ & $G_{\max }$ & AM & $C_{50}$ & $G_{\max }$ & AM & $C_{50}$ & $G_{\max }$ & $\mathrm{AM}$ \\
\hline L-Alanine & $6.0 \times 10^{-5}$ & $2 \cdot 4$ & $22 \cdot 6$ & $4.6 \times 10^{-4}$ & $2 \cdot 0$ & $27 \cdot 2$ & $7.6 \times 10^{-3}$ & $1 \cdot 27$ & $41 \cdot 2$ \\
\hline L-Valine & $3.7 \times 10^{-3}$ & $2 \cdot 4$ & $23 \cdot 8$ & $2.6 \times 10^{-2}$ & $2 \cdot 0$ & $35 \cdot 2$ & $>2.0 \times 10^{-1 *}$ & 0.8 & $49 \cdot 4$ \\
\hline $\begin{array}{l}\text { L- } \alpha \text {-Amino- } \\
\text { butyrate }\end{array}$ & $4.2 \times 10^{-4}$ & $3 \cdot 3$ & 23.9 & $2.8 \times 10^{-3}$ & $2 \cdot 35$ & $24 \cdot 1$ & $2.8 \times 10^{-2}$ & 1.45 & $27 \cdot 6$ \\
\hline $\begin{array}{l}\text { DL- } \beta \text {-Amino- } \\
\text { butyrate }\end{array}$ & $8.5 \times 10^{-4}$ & $2 \cdot 2$ & $22 \cdot 3$ & $7.7 \times 10^{-3}$ & $1 \cdot 8$ & $30 \cdot 5$ & $>2.3 \times 10^{-2 *}$ & 1.45 & $53 \cdot 5$ \\
\hline Cycloleucine & $>2.0 \times 10^{-2 *}$ & $2 \cdot 0$ & $24 \cdot 8$ & $>10^{-1}$ & NM & NM & $>10^{-1}$ & NM & NM \\
\hline
\end{tabular}

NM, Not measurable.

* The curve for the determination of $C_{50}$ did not reach a plateau and the concentration given is that for $50 \%$ of the observed maximum germination rate. The range of concentrations of germinant used to obtain estimates of germination parameters was from $10^{-5}$ to $10^{-1} \mathrm{M}\left(3 \times 10^{-1} \mathrm{M}\right.$ for L-valine $)$.

Table 2. Effects of the addition of glucose, fructose and $\mathrm{KCl}$ to $\mathrm{L}$-alanine and $\mathrm{L}$-valine on the germination of wild-type, GerA38 and GerA44 spores

\begin{tabular}{|c|c|c|c|c|}
\hline \multirow[b]{3}{*}{ Strain } & \multicolumn{4}{|c|}{$C_{50}$ value $(\mathrm{M})$} \\
\hline & \multicolumn{4}{|c|}{ Germinant*: } \\
\hline & Ala & $\mathrm{Ala}+\mathrm{Glc}+\mathrm{Fru}+\mathrm{KCl}$ & Val & $\mathrm{Val}+\mathrm{Glc}+\mathrm{Fru}+\mathrm{KCl}$ \\
\hline Wild-type & $6.25 \times 10^{-5}$ & $3.15 \times 10^{-5}$ & $4.6 \times 10^{-3}$ & $3.3 \times 10^{-3}$ \\
\hline GerA38 & $1.4 \times 10^{-3}$ & $1.4 \times 10^{-4}$ & $3.0 \times 10^{-2}$ & $1.4 \times 10^{-2}$ \\
\hline GerA44 & $1.7 \times 10^{-2}$ & $9.5 \times 10^{-4}$ & $2.0 \times 10^{-1}$ & $7.0 \times 10^{-2}$ \\
\hline
\end{tabular}

wild-type. The response of GerA38 to L-valine was similarly altered but comparisons between $C_{50}$ values of GerA44 and the wild-type in L-valine could not be made as the curve for the determination of $C_{50}$ of this mutant in L-valine did not reach a plateau. The observation that the mutants were defective in germinating in each of the amino acids tested suggests that these amino acids share a common role in germination.

\section{Effect of glucose, fructose and $\mathrm{KCl}$ on the germination of wild-type and mutant spores in $\mathrm{L}$-alanine and $\mathrm{L}$-valine}

Since spores of some germination mutants unable to germinate in L-alanine can do so on addition of glucose, fructose and $\mathrm{KCl}$ (Prasad et al., 1972), the effects of these adjuncts on the germination of wild-type, GerA38 and GerA44 spores in L-alanine and L-valine was tested. Their presence reduced the $C_{30}$ values of the mutants by approximately 10 - and 3-fold in L-alanine and L-valine, respectively, although full correction to the wild-type $C_{50}$ values was not observed (Table 2). The spores of these particular preparations germinated exceptionally slowly and the normal and characteristic $G_{\max }$ difference between wild-type and mutant spores (Table 1) was not observed. The reason for this is not clear but may have been due to the fact that these spore preparations were particularly well washed (approximately 20 times instead of the usual 10 times). Addition of glucose, fructose and $\mathrm{KCl}$ increased the $G_{\max }$ of both wild-type and mutant spores from approximately 0.6 to $1.2\left(\Delta A_{580} \mathrm{~min}^{-1}\right)$. In the absence of adjuncts the AM values of wild-type, GerA38 and GerA44 spores were, 

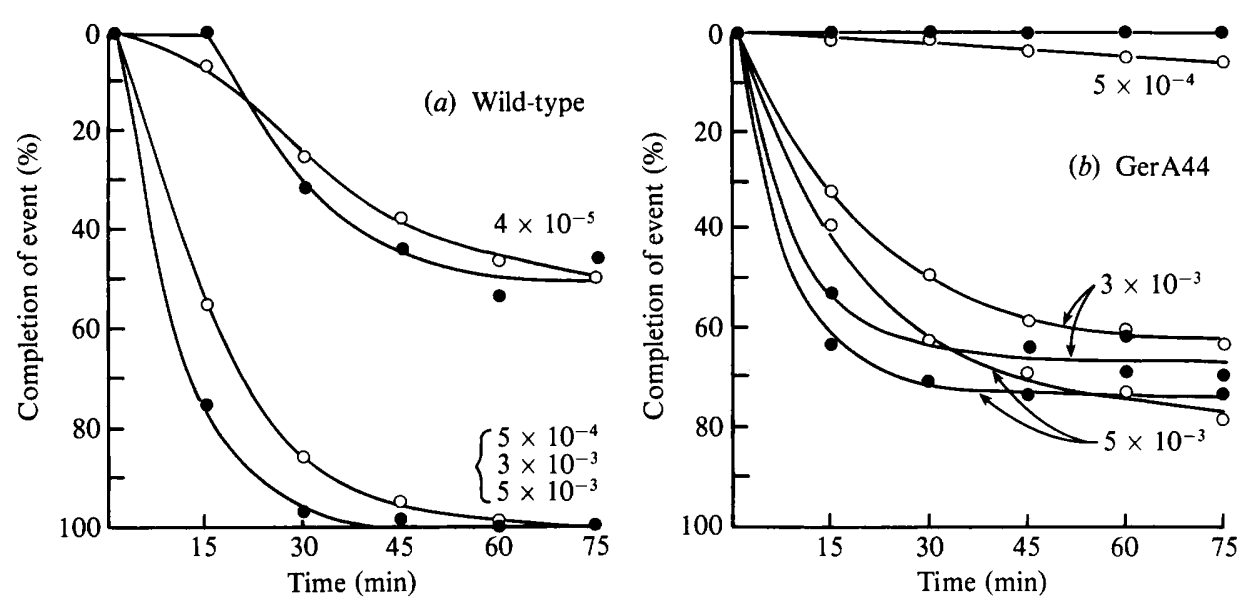

Fig. 2. Germination of wild-type (a) and GerA44 (b) spores in L-alanine at different concentrations (M, indicated on the figures), monitored by loss of heat resistance (O) or absorbance (O). Completion of event (\%) was calculated as $100 \times$ (Loss of absorbance or heat resistance of wild-type or mutant spores after time $t) /\left(\right.$ Loss of absorbance or heat resistance of wild-type spores after $75 \mathrm{~min}$ in $5 \times 10^{-3}$ M-L-alanine).

respectively, $61 \cdot 1,70.2$ and $77.3 \mathrm{~min}$ in L-alanine. In L-alanine plus glucose, fructose and $\mathrm{KCl}$ they were, respectively, $41.5,45.1$ and $45.7 \mathrm{~min}$. Similar changes were observed in L-valine. Thus, the adjuncts did not fully correct the deficiencies of the mutants.

Previously isolated GerA mutants do not germinate even in. $3 \times 10^{-1} \mathrm{M}$-L-alanine (Moir et al., 1979) but will do so in $\mathrm{L}$-alanine plus glucose, fructose and $\mathrm{KCl}$. The $\mathrm{L}$-alanine $C_{50}$ values of mutants GerA1, 7, 11 and 16 were measured under these conditions and were, respectively, $7.2 \times 10^{-4}, 8.0 \times 10^{-4}, 8.0 \times 10^{-4}$ and $3.6 \times 10^{-4} \mathrm{M}$, i.e. very close to those of GerA38 and GerA44 (Table 2).

\section{Germination in asparagine plus glucose, fructose and $\mathrm{KCl}$ and in Penassay broth}

To determine whether the deficiencies of the spores of GerA38 and GerA44 were specific for L-alanine and structurally related amino acids, germination was monitored in a range of concentrations of $\mathrm{L}$-asparagine plus glucose, fructose and $\mathrm{KCl}$ ( $\mathrm{L}$-asparagine is nongerminative alone). GerA38 and GerA44 spores had $C_{50}$ values of $5.6 \times 10^{-4} \mathrm{M}$ and $3.7 \times$ $10^{-4} \mathrm{M}$, respectively, which were similar to that of wild-type spores $\left(4.6 \times 10^{-4} \mathrm{M}\right)$. However, spores of GerA44 exhibited a longer AM in PAB than did both the wild-type and GerA38, whose spores were not defective in this medium. This observation further underlines the differences between GerA38 and GerA44, but it is difficult to interpret since PAB is an undefined medium. Differences may be due to the amino acid composition of PAB or could imply that the germination deficiency or deficiencies of GerA44 are less specific than those of GerA38.

\section{Loss of heat resistance of wild-type and mutant spores}

Since loss of absorbance is a relatively late event in germination its measurement does not reveal at which stage(s) during the initiation of germination GerA38 and GerA44 are defective. One of the earliest measurable events in germination is loss of heat resistance (Levinson \& Hyatt, 1966). Germination of wild-type and GerA44 spores was therefore monitored by measurement of loss of heat resistance in parallel with loss of absorbance (Fig. 2). Both properties showed a similar dependence on germinant concentration for both wild-type and mutant spores, although GerA44 spores failed to lose heat resistance as well as absorbance in $5 \times 10^{-4} \mathrm{M}$-L-alanine. Thus, spores of GerA44 are deficient at a very early stage of germination which precedes loss of heat resistance and subsequent changes. 
Table 3. Inhibition of germination of wild-type, GerA38 and GerA44 spores by D-alanine

\begin{tabular}{|c|c|c|c|c|c|c|c|c|c|}
\hline \multirow{3}{*}{$\begin{array}{c}\text { Ratio of } \\
\text { alanine } \\
\text { isomers } \\
\text { L : D }\end{array}$} & \multicolumn{3}{|c|}{ Wild-type } & \multicolumn{3}{|c|}{ GerA38 } & \multicolumn{3}{|c|}{ GerA44 } \\
\hline & & $\begin{array}{l}\text { Ala } \\
\text { (M) }\end{array}$ & & & $\begin{array}{l}\text { Ala } \\
\text { (M) }\end{array}$ & & $\begin{array}{l}10^{1} \\
\text { cor }\end{array}$ & $\begin{array}{l}\text { Ala } \\
\text { (M) }\end{array}$ & \\
\hline & $\mathbf{L}$ & $\overbrace{D}$ & $\begin{array}{c}\text { Inhibition* } \\
(\%)\end{array}$ & L & D & $\begin{array}{c}\text { Inhibition* } \\
(\%)\end{array}$ & L & D & $\begin{array}{c}\text { Inhibition* } \\
\text { (\%) }\end{array}$ \\
\hline $0: 1$ & 0 & 1 & 100 & 0 & 5 & 100 & 0 & 4.5 & 100 \\
\hline $1: 1$ & 1 & 1 & 95 & 5 & 5 & 100 & $4 \cdot 5$ & $4 \cdot 5$ & 100 \\
\hline $2: 1$ & 1 & 0.5 & 94 & 5 & $2 \cdot 5$ & 100 & $4 \cdot 5$ & $2 \cdot 25$ & 100 \\
\hline $4: 1$ & 1 & 0.25 & 55 & 5 & $1 \cdot 25$ & 100 & 4.5 & $1 \cdot 12$ & 100 \\
\hline $8: 1$ & 1 & 0.125 & 33 & 5 & 0.625 & 96 & $4 \cdot 5$ & 0.56 & 100 \\
\hline $10: 1$ & 1 & 0.1 & 23 & 5 & 0.5 & 88 & 4.5 & 0.45 & 100 \\
\hline $20: 1$ & 1 & 0.05 & 14 & 5 & 0.25 & 68 & 4.5 & 0.225 & 93 \\
\hline
\end{tabular}

\footnotetext{
* Calculated as $100 \times\{1-[($ Germination rate in the presence of D-alanine $) /($ Germination rate in the absence of D-alanine)]\}.
}

\section{Inhibition of spore germination by $\mathrm{D}$-alanine}

One possible explanation for the germination properties of GerA38 and GerA44 spores is that they are specifically defective in a receptor for $\mathrm{L}$-alanine and its analogues as germinants. Since D-alanine acts as a competitive inhibitor of germination and may share common receptors with L-alanine (Woese et al., 1958), the germination response of mutant and wild-type spores was determined in the presence of $D$-alanine. The concentrations of $L$-alanine chosen were the $C_{100}$ values (Fig. $1 b$ ) for mutant and wild-type spores so that spores of each strain were in equivalent, optimal concentrations of L-alanine. The ratio of L-alanine to D-alanine was varied by diluting the D-alanine and keeping the L-alanine concentration constant. Under these conditions if the ability of the mutant spores to respond to L-alanine and D-alanine was lowered by the same factor, the extent of inhibition by D-alanine should be the same for the wild-type and mutants. However, both GerA38 and GerA44 were relatively more sensitive to inhibition, with the difference between the wild-type and mutant being more apparent for GerA44 (Table 3). This indicates that the affinity of the mutants for D-alanine is clearly not reduced to the same extent as that for L-alanine, and in the case of GerA38 may be unaltered or so small as to be unnoticed since approximately $5 \times 10^{-3} \mathrm{M}$-D-alanine was required to inhibit germination of spores of both the wild-type and this mutant by $90 \%$. However, the concentration of D-alanine resulting in this degree of inhibition of germination of spores of GerA44 was approximately 5 -fold higher $\left(2.25 \times 10^{-2} \mathrm{M}\right)$. Thus, the affinity of spores of this mutant for both $\mathbf{L}$ - and $\mathbf{D}$-alanine appears to have changed. With glucose, fructose and $\mathrm{KCl}$ present, the inhibitory effect of D-alanine on mutant and wild-type spores germinating in equivalent $\left(C_{100}\right)$ concentrations of $\mathrm{L}$-alanine was reduced, but the ratios of $\mathrm{L}$-alanine to $\mathrm{D}$-alanine resulting in $50 \%$ inhibition were, respectively, approximately $1 \cdot 5: 1$, 2:1 and 4.5:1 for the wild-type, GerA38 and GerA44 indicating that mutant spores also remained more sensitive to $\mathrm{D}$-alanine under these conditions. The concentrations of $\mathrm{D}$-alanine resulting in $50 \%$ inhibition were, respectively, $5 \times 10^{-4}$ to $2.5 \times 10^{-4} \mathrm{M}, 10^{-2}$ to $2.5 \times 10^{-3} \mathrm{M}$ and $2 \times 10^{-2} \mathrm{M}$ for wild-type, GerA38 and GerA44 spores. Thus, higher concentrations of D-alanine were needed to inhibit germination of spores of both mutants to the same extent as wild-type spores, again suggesting that the affinity of the mutant spores for D-alanine had been reduced.

The results of experiments with $O$-carbamyl-D-serine, an inhibitor of L-alanine racemase which stimulates germination in L-alanine by inhibiting the conversion of L-alanine to D-alanine (Jones \& Gould, 1968), are consistent with the greater sensitivity of GerA44 to D-alanine inhibition compared with GerA38 and the wild-type. At equimolar concentrations with the germinant, $O$-carbamyl-D-serine had little effect on the germination of spores of the 
wild-type and GerA38 but increased both the rate and final extent of germination of spores of GerA 44 by $40 \%$ and $20 \%$; respectively.

The apparent change in affinity of spores of GerA44 for both L- and D-alanine is consistent with the hypothesis that both isomers bind to a common receptor which is defective in this mutant and probably also in GerA38. The observation that $2.5 \times 10^{-3} \mathrm{M}$-D-alanine completely inhibited germination in $5 \times 10^{-2} \mathrm{M}$-L-valine together with the above results supports the conclusion that the receptor is also common to L-valine. However, $3 \times$ $10^{-3} \mathrm{M}$-D-valine did not inhibit germination in an equimolar concentration of L-valine, and thus the receptor may not be accessible to $D$-valine.

\section{Response of vegetative cells of germination mutants to $\mathrm{L}$-alanine}

The vegetative cells of germination mutants might also be defective in their response to L-alanine. To explore this possibility the chemotactic responses of the wild-type and mutants to L-alanine and their abilities to use it as a source of carbon or nitrogen were compared. Mutants GerA1, GerA7 and GerA11 were used in some of these experiments because their spores are unable to germinate even in $3 \times 10^{-1} \mathrm{M}$-L-alanine and thus any differences between the responses of their vegetative cells and those of the wild-type might be correspondingly large. GerA11 and GerA44 showed normal chemotactic responses to concentrations of L-alanine ranging from $10^{-9}$ to $10^{-1} \mathrm{M}$, the threshold concentration (Ordal \& Gibson, 1977) being approximately $1 \times 10^{-7} \mathrm{M}$ for both the wild-type and mutants. Growth rates of the wild-type, GerA1 and GerA7 were each measured with L-alanine as either carbon or nitrogen source. Although variation between duplicate experiments ranged from 3 to $30 \%$, the mean generation times calculated for the mutants were similar to those of the wild-type (186 and $210 \mathrm{~min}$ for carbon and nitrogen source, respectively). Thus, it is unlikely that ger $A$ mutations affect the response of vegetative cells as well as of spores to L-alanine.

\section{Dipicolinic acid contents}

Since dipicolinic acid is a major constituent of bacterial spores (Murrell, 1969) and may play an important role in germination (Hanson et al., 1972), the dipicolinic acid contents of GerA38 and GerA44 spores were compared with that of wild-type spores in two ways (see Methods). Although a 10 to $27 \%$ variation in results with different spore preparations was obtained they were substantially the same for both the mutants and the wild-type.

\section{Mapping of gerA mutations}

The $\mathrm{Ger}^{-}$phenotypes of spore-containing colonies of GerA38 and GerA44 could be clearly distinguished from each other and from the wild-type by their tetrazolium reactions; both were white, but those of GerA38 had a pink ring around their periphery. In transduction experiments between the mutants as donors and strains BD111 (cysB3 thr-5 trpC2) or BD92 (cysB3 hisA1 trpC2) as recipients using phage PBS1, the mean cotransduction frequencies for ger $A 38$ and ger $A 44$ were 78 and $71 \%$ with $c y s B$, and 42 and $44 \%$ with $t h r-5$, respectively. In addition, gerA 44 was $11 \%$ cotransduced with his $A$. These linkages are similar to those of 26 other GerA mutations (Moir et al., 1979).

Other GerA mutants are phenotypically different from GerA38 and GerA44 in that their spores are unable to germinate in L-alanine plus $\mathrm{KCl}$ unless glucose and fructose are also present. The possible correlation between map location and germination phenotype of GerA38 and GerA44 and 14 other GerA mutants differing in their ability to germinate in PAB or in their temperature dependence (Moir et al., 1979) was tested in mapping experiments using phage SPP1. This phage carries a small fragment of DNA of approximately 20 megadaltons (Ferrari et al., 1978) which should have permitted a more precise location of ger mutations than was possible using PBS1 (190 megadaltons: Hunter et al., 1967). The GerA mutants were used as donors in two-factor crosses with JH404 (citG4 $\operatorname{trpC2}$ ) as recipient and $\mathrm{CitG}^{+}$recombinants were selected (citG4 maps between thr-5 and 
Table 4. Cotransduction of gerA mutations with citG4

\begin{tabular}{|c|c|c|c|c|c|}
\hline \multirow[b]{2}{*}{$\begin{array}{c}\text { GerA } \\
\text { mutant }\end{array}$} & \multicolumn{3}{|c|}{ Germination ${ }^{\dagger}$} & \multicolumn{2}{|c|}{ Transduction } \\
\hline & $\begin{array}{l}\mathrm{Ala}+ \\
\mathrm{KCl}\end{array}$ & $\begin{array}{l}\text { Germinant } \neq: \\
\text { Asn + Glc + } \\
\text { Fru + KCl }\end{array}$ & PAB & $\begin{array}{c}\text { No. } \\
\text { screened }\end{array}$ & $\begin{array}{l}\text { Cotransduction } \\
\text { with citG4 (\%) }\end{array}$ \\
\hline $\begin{array}{l}38 \\
44\end{array}$ & $\begin{array}{l}+1- \\
+1-\end{array}$ & $\begin{array}{l}+ \\
+\end{array}$ & $\begin{array}{l}+1- \\
+1-\end{array}$ & $\begin{array}{l}120 \\
120\end{array}$ & $\begin{array}{l}84 \\
72\end{array}$ \\
\hline $\begin{array}{r}1 \\
3 \\
7 \\
15 \\
2\end{array}$ & $\begin{array}{l}- \\
- \\
- \\
- \\
\text { hs }\end{array}$ & $\begin{array}{l}+ \\
+ \\
+ \\
+ \\
+\end{array}$ & $\begin{array}{l}+ \\
+ \\
+ \\
+ \\
+\end{array}$ & $\begin{array}{l}112 \\
137 \\
111 \\
104 \\
110\end{array}$ & $\begin{array}{l}71 \\
73 \\
78 \\
85 \\
74\end{array}$ \\
\hline $\begin{array}{l}11 \\
13 \\
14\end{array}$ & $\begin{array}{l}- \\
- \\
-\end{array}$ & $\begin{array}{l}+ \\
+ \\
+\end{array}$ & $\begin{array}{l}- \\
- \\
-\end{array}$ & $\begin{array}{r}95 \\
120 \\
113\end{array}$ & $\begin{array}{l}89 \\
75 \\
79\end{array}$ \\
\hline $\begin{array}{l}4 \\
5 \\
6 \\
9\end{array}$ & $\begin{array}{l}- \\
- \\
- \\
-\end{array}$ & $\begin{array}{l}+ \\
+ \\
+ \\
+\end{array}$ & $\begin{array}{l}+1- \\
+1- \\
+1- \\
+1-\end{array}$ & $\begin{array}{l}108 \\
133 \\
120 \\
164\end{array}$ & $\begin{array}{l}81 \\
89 \\
85 \\
89\end{array}$ \\
\hline 12 & hs & + & hs & 112 & 82 \\
\hline 16 & - & + & hs & 128 & 78 \\
\hline
\end{tabular}

* GerA mutants are grouped according to the germination phenotype of their spores (Moir et al., 1979).

$\dagger+,+/-$ and - , normal, poor and no germination, respectively; hs, heat sensitive.

$\ddagger$ Ala, L-Alanine; Asn, L-asparagine; Fru, fructose; Glc, glucose; PAB, Penassay broth.

$\S$ The addition of $\mathrm{KCl}$ to Ala stimulates the rate of spore germination but does not alter the qualitative differences between the germination of wild-type and mutant spores.

cys $B 3$ and is close to ger $A$ : Rutberg and Hoch, 1970; Moir et al., 1979). The results (Table 4) indicate that $\operatorname{ger} A 38$ and ger $A 44$ map within a cluster of ger $A$ mutations that are 71 to $89 \%$ cotransduced with citG4.

There was clearly no correlation between germination phenotype and cotransduction frequency. This was confirmed by a contingency $\chi^{2}$ test of the cotransduction frequencies, which, however, also indicated that the probability of obtaining such a distribution of frequencies due to sampling error alone was $0.001 \%$. Thus, it is possible that the differences reflect the range of linkage of gerA mutations to citG4.

The u.v.-irradiation employed to obtain enough transductants to measure the cotransduction frequencies could well have affected linkage. Cotransduction frequencies of gerA2, 16 and 14 with citG4 determined with and without u.v.-irradiation differed by less than $2 \%$, but those of gerA3 and gerA 4 were 88 and $93 \%$, respectively, i.e. 15 and $12 \%$ higher than without irradiation. In the last two cases, however, the total numbers of transductants screened were 61 and 46 , respectively, so that sampling error may have exaggerated the differences. Thus, u.v.-irradiation does not appear seriously to affect linkage. Crosses involving gerA1, 9, 11 and 44 were repeated (with u.v. treatment) using different lysates. The differences between cotransduction frequencies in the two experiments were, respectively, 1 , 0,2 and $7 \%$. Thus, as previously, sampling error and/or slight variations in experimental procedure may have contributed to the differences in cotransduction frequency in Table 4.

All gerA mutations clearly map very close to each other but more detailed fine structure mapping is necessary to determine their relative order and whether GerA mutants other than GerA38 and GerA44 are defective in the same gene(s) as these two mutants. 


\section{Attempted detection of gerA nonsense mutations}

GerA38 and gerA44 and 17 other gerA mutations $(1,2,3,4,6,7,9,10,11,13,14,16,28$, $31,32,86$ and 97) were screened for amber suppressibility. Thr-5 is a nonsense mutation and was available in ger $A \operatorname{trp} C 2$ recombinants from transduction crosses but it reverted at high frequency. Thus, the first step was to transduce these strains with phage PBS1 grown on strain BD34 (leuA8thr-5, and metB5-another more stable nonsense mutation), selecting $\mathrm{Trp}^{+}$recombinants and isolating $t h r-5$ gerA metB5 derivatives resulting from approximately $4 \%$ cotransduction of metB5 and $\operatorname{trpC2}{ }^{+}$. Such derivatives carrying each of the gerA mutations were then transduced with phage PBS1 or SPP1 grown on MB54, a derivative of BD34 with the same auxotrophic markers and a nonsense suppressor sup-3, selecting prototrophic recombinants. Suppression of the $\mathrm{Ger}^{-}$phenotype was then tested in 50 recombinants from each cross using the tetrazolium overlay method, following confirmation of transfer of the suppressor to a sample of six of them by their sensitivity to phage SPO-1 sus-5. None of the nonsense suppressed $\mathrm{Met}^{+}$recombinants from any of the crosses were tetrazolium red. It is therefore unlikely that any of the 19 GerA strains screened were nonsense mutants although partial suppression may not have been detected by this method.

\section{DISCUSSION}

GerA38 and GerA44 are deficient at a stage which occurs very early in germination preceding loss of heat resistance and absorbance. The deficiency appears to be specific to L-alanine and structurally related amino acid germinants, such as $\mathrm{L}$ - $\alpha$-aminobutyrate, $\beta$-aminobutyrate, $\mathrm{L}$-valine and cycloleucine, since germination in L-asparagine plus glucose, fructose and $\mathrm{KCl}$ is normal. The deficiency simultaneously affects germinant concentration dependence, germination rate and average microlag and is partially corrected by increasing the concentration of germinant or by adding glucose, fructose and $\mathrm{KCl}$.

One explanation for some of these properties is that GerA38 and GerA44 are defective in a germinant receptor which is common to L-alanine and analogues. It is likely that structurally related amino acids bind to the same receptors as L-alanine but with lower efficiency. In common with Woese et al. (1958), we observed that each germinative amino acid has a $-\mathrm{CH}_{3}$ or $-\mathrm{CH}_{2}-$ group within one carbon atom of the $\alpha-\mathrm{C}$ or $-\mathrm{COOH}$ and a free $-\mathrm{NH}_{2}$ group, and that effectiveness as a germinant decreases with the complexity of the side-chain to which the $-\mathrm{CH}_{3}$ group is attached and the distance of the $-\mathrm{NH}_{2}$ group from the $\alpha-\mathrm{C}$. This correlation between germinant efficiency and structure supports the hypothesis that this group of amino acids shares a common receptor. Consistent with this is the observation that $\mathbf{D}$-alanine and $O$-carbamyl-D-serine at high concentrations inhibit germination in both L-alanine and $\mathrm{L}$-valine. Thus, we conclude that $\mathrm{L}$ - and $\mathrm{D}$-alanine and structurally related analogues share a common receptor. The simplest explanation for the reduced affinity of spores of GerA38 and GerA44 for L- and D-alanine and structurally related amino acids is that their mutation(s) cause a structural change in this receptor which reduces its binding efficiency. Alternatively, GerA38 and GerA44 could be defective at a stage of germination which does not involve binding of the germinant to a receptor but is still germinant specific. So far, attempts to distinguish between these two hypotheses by directly measuring the D-alanine binding capacities of mutant and wild-type spores have been inconclusive. However, L-valine at $10^{-3} \mathrm{M}$ (subgerminal) does not inhibit germination of wild-type spores in L-alanine at $5 \times$ $10^{-5}$ M (Sammons, 1980). This accords with germinant specificity reflecting relative binding efficiency since, assuming that the number of binding sites is limited, then if L-alanine and $\mathrm{L}$-valine bound equally well the addition of subgerminal amounts of $\mathrm{L}$-valine should compete with L-alanine and inhibit the germination response.

The changes in $C_{50}, G_{\max }$ and $\mathrm{AM}$ of mutant spores suggest that a single mutational event can cause changes in all three parameters. AM is likely to be dependent on the time taken for the germinant to reach a receptor, bind to it and initiate germination, especially if, as 
suggested by Woese et al. (1958), initiation occurs only after a critical number of events have taken place. If the rate-limiting step were that of binding of germinant to receptor, a change in binding affinity could affect $\mathrm{AM}$ as well as $C_{50}$. Changes in $G_{\max }$ are more difficult to explain since $G_{\max }$ reflects the homogeneity of the spore population with respect to microlag. It is not clear why the distribution of microlag should have changed in mutant spore populations; those of GerA38 and GerA44 appear to be more heterogeneous than the wild-type. Qualitative and quantitative differences in the number of ions and other germination stimulants, such as sugars and amino acids leached from spontaneously germinating spores, which may influence microlag and $G_{\max }$ could contribute to the differences in AM and $G_{\max }$ values of wild-type and mutant spores. It may be significant that particularly well-washed mutant and wild-type spore preparations did not show the characteristic difference in $G_{\max }$ although AM values did differ.

The effects of glucose, fructose and $\mathrm{KCl}$ on $C_{50}, G_{\max }$ and $\mathrm{AM}$ underline the relationship between these three parameters. That of $\mathrm{KCl}$ probably reflects a non-specific requirement of germination for ions which may be required for the activation of enzymes to disrupt the stability of spore structure such as the cortex, membranes or calcium dipicolinate complex (Fleming \& Ordal, 1964; Gould, 1969; Gould \& Dring, 1972; Ellar, 1978) or to provide a favourable ionic environment for the interaction of germinant and receptors. Glucose and fructose may act synergistically with germinative amino acids, binding to specific receptors, or may act at some later stage of germination. However, both were required together with $\mathrm{KCl}$ and $\mathrm{L}$-alanine for maximum stimulation of germination of mutant or wild-type spores (Sammons, 1980). It is not known whether they are metabolized by germinating spores of $B$. subtilis during the period prior to loss of absorbance. The ability of wild-type spores to germinate in $\mathrm{L}^{-} \alpha$ - and $\beta$-aminobutyrate, $\mathrm{L}$-valine and cycloleucine suggests that fructoneogenesis of the germinant is not necessary for spores of this strain of B. subtilis, and, indeed, the response to cycloleucine could indicate that germination has no prerequisite for any metabolism of the germinant. However, it is still possible that initiation of germination could follow metabolism of an endogenous substrate triggered by binding of specific germinants.

In examining the ability of GerA mutants to use L-alanine as a source of carbon and nitrogen and to respond to it as a chemoattractant, the possibility that an L-alanine receptor present in the vegetative cell might eventually become a spore germinant receptor was being explored. This is unlikely since GerA mutant vegetative cells respond normally to L-alanine although its uptake at low concentrations by such cells has not been tested and could be affected. If the spores of GerA mutants possess abnormal L-alanine receptors specific for the germination process, spore membranes are likely candidates for the location and action of germinant receptors. In fact, Rossignol \& Vary (1979) may have located the receptor for the germinant proline in the membranes of spores of Bacillus megaterium QMB1551. However, changes in the vegetative cell membrane as it is converted into those of the forespore (Koncewitz et al., 1977) may preclude functional amino acid receptors remaining in spore membranes.

GerA38 and gerA44 mutations may map within the same gene(s) as those resulting in more severely defective phenotypes of GerA mutants. One explanation for the different phenotypes of GerA mutants is that their mutations cause defects in the germinant receptor which affect the binding site in different ways. Consideration of GerA mutants as a single group seems justified since the $C_{50}$ values of their spores in L-alanine plus glucose, fructose and $\mathrm{KCl}$ are similar. The spore may have two receptors for L-alanine, one of high affinity which binds $\mathrm{L}$-alanine and analogues alone and another which binds L-alanine (and analogues) with lower affinity in the presence of glucose, fructose and $\mathrm{KCl}$. The former would be deficient in GerA mutants, being partially operative in GerA38 and GerA44 and completely blocked in others. In L-alanine plus glucose, fructose and $\mathrm{KCl}$ the $C_{50}$ value would then be a measure of the total binding affinity of both receptors. This hypothesis is supported by the observation that under 
these conditions the $C_{50}$ value of GerA38 is slightly lower than that of the other mutants but still higher than that of wild-type spores.

Although gerA mutations are very close to $c i t G$, which is the structural gene for fumarase (Rutberg \& Hoch, 1970), fumarase activities in vegetative cells of GerA5, GerA11 and GerA44 were normal (Sammons, 1980). Thus, it is unlikely that the mutations of at least these three GerA mutants are within or affect expression of citG. Finally, the failure to detect ger $A$ nonsense mutations amongst the 19 tested does not necessarily imply failure of gerA gene(s) to code for protein(s). For example, lack of such mutants could be due to inviability of their vegetative cells or spores if the gerA protein is essential for vegetative growth or sporulation or, for example, if a complete polypeptide is necessary for spore viability perhaps in a structural capacity. Also GerA nonsense mutants could have been excluded by the selection procedures used to obtain them if their spores failed to germinate under conditions used to recover most GerA spores or their absence might be due simply to the screening of insufficient mutants.

Further genetic and functional studies of GerA mutants and the GerA region of the chromosome could be of great value in analysis of the nature and control of early events in germination.

We are grateful to colleagues in the laboratory for discussion, especially Dr E. Lafferty for advice in the initiation of the work described. Mrs S. Haley, Dr H. Howell and Mrs J. Yeomans gave valuable technical assistance. We thank Professor G. W. Gould and Mr G. J. Dring of Unilever Research and Dr D. Ellar and his colleagues at Department of Biochemistry, Cambridge University, for advice and help to R. L. S. during periods spent in their laboratories. This work was supported by the Science Research Council in the form of a CASE studentship to R. L.S., a Research Fellowship to A.M. and a research grant to D.A.S.

\section{REFERENCES}

AdLeR, J. (1973). A method for measuring chemotaxis and use of the method to determine optimum conditions for chemotaxis by Escherichia coli. Journal of General Microbiology 74, 77-91.

ELLAR, D. J. (1978). Spore specific structures and their function. Symposia of the Society for General Microbiology 28, 295-325.

Ferrari, E., Canosi, U., Galizzi, A. \& Mazza, G. (1978). Studies on transduction process by SPP 1 phage. Journal of General Virology 41, 563-572.

Fleming, H. P. \& ORDAL, Z. J. (1964). Responses of Bacillus subtilis spores to ionic environments during sporulation and germination. Journal of Bacterio$\log y 88,1529-1537$.

Freese, E., Park, S. W. \& Cashel, M. (1964). The developmental significance of alanine dehydrogenase in Bacillus subtilis. Proceedings of the National Academy of Sciences of the United States of America 51, 1164-1172.

Georgopoulos, C. P. (1969). Suppressor system in Bacillus subtilis 168. Journal of Bacteriology 97, 1397-1402.

Goldman, M. \& Blumenthal, H. J. (1964). Pathways of glucose catabolism in Bacillus cereus. Journal of Bacteriology 87, 377-386.

Gould, G. W. (1969). Germination. In The Bacterial Spore, pp. 397-444. Edited by G. W. Gould \& A. Hurst. New York: Academic Press.

Gould, G. W. \& DRING, G. J. (1972). Biochemical mechanisms of spore germination. In Spores $V$, pp. 401-408. Edited by H. O. Halvorson, R. Hanson \& L. L. Campbell. Washington, D.C.: American Society for Microbiology.
Hanson, R. S., Curry, M. W., Garner, J. V. \& Halvorson, H. O. (1972). Mutants of Bacillus cereus strain $\mathrm{T}$ that produce thermoresistant spores lacking dipicolinate and have low levels of calcium. Canadian Journal of Microbiology 18, 1139-1143.

Hunter, B. I., Yamagishi, H. \& TAKAIIASHI, I. (1967). Molecular weight of bacteriophage PBS1 deoxyribonucleic acid. Journal of Virology 1, 841842.

Janssen, F. W., Lund, A. J. \& Anderson, L. E. (1958). Colorimetric assay for dipicolinic acid in bacterial spores. Science 127, 26-27.

JoNES, A. \& Gould, G. W. (1968). Stimulation of germination of bacterial spores by analogues of D-alanine. Journal of General Microbiology 53, 383-394.

Koncewitz, M. A., Ellar, D. J. \& Postgate, J. A. (1977). Metabolism of membrane lipids during bacterial spore germination and outgrowth. Biochemical Society Transactions 5, 118-119.

LAFFerTy, E. \& MoIR, A. (1977). Further studies on conditional germination mutants of Bacillus subtilis 168. In Spore Research 1976, pp. 87-105. Edited by A. N. Barker, J. Wolf, D. J. Ellar, G. J. Dring \& G. W. Gould. London: Academic Press.

Levinson, H. S. \& HyATT, M. T. (1966). Sequence of events during Bacillus megaterium spore germination. Journal of Bacteriology 91, 1811-1818.

MoIR, A., LAFferTy, E. \& SMITH, D. A. (1979). Genetic analysis of spore germination mutants of Bacillus subtilis 168: the correlation of phenotype with map locations. Journal of General Microbio$\log y 111,165-180$. 
Murrell, W. G. (1969). Chemical composition of spores and spore structures. In The Bacterial Spore, pp. 215-273. Edited by G. W. Gould \& A. Hurst. New York: Academic Press.

Ordal, G. W. \& Gibson, K. J. (1977). Chemotaxis towards amino acids by Bacillus subtilis. Journal of Bacteriology 129, 151-155.

Prasad, C., Diesterhaft, M. \& Freese, E. (1972). Initiation of spore germination in glycolytic mutants of Bacillus subtilis. Journal of Bacteriology 110 , 321-328.

Rossignol, D. P. \& VARY, J. C. (1979). L-Proline site for triggering Bacillus megaterium spore germination. Biochemical and Biophysical Research Communications 89, 547-551.

Rutberg, B. \& Hoch, J. A. (1970). Citric acid cycle: gene-enzyme relationships in Bacillus subtilis. Journal of Bacteriology 104, 826-833.

Sammons, R. L. (1980). Studies of the initiation of spore germination in Bacillus subtilis 168. Ph.D. thesis, University of Birmingham.

ScotT, I. R. \& ElLAR, D. J. (1978a). Study of calcium dipicolinate release during bacterial spore germination by using a new, sensitive assay for dipicolinate. Journal of Bacteriology 135, 133-137.

ScotT, I. R. \& EllaR, D. J. (1978b). Metabolism of and triggering of germination of Bacillus megaterium. Concentrations of amino acids, organic acids, adenine nucleotides and nicotinamide nucleotides during germination. Biochemical Journal 174, 627-634.

SCOTT, I. R. \& EllaR, D. J. (1978c). Metabolism and the triggering of germination of Bacillus megaterium. Use of $L_{-}\left[{ }^{3} \mathrm{H}\right]$ alanine and tritiated water to detect metabolism. Biochemical Journal 174, $635-640$.

Smith, D. A., MoIR, A. \& SAmmons, R. (1978). Progress in genetics of spore germination in Bacillus subtilis. In Spores VII, pp. 158-163. Edited by G. Chambliss \& J. C. Vary. Washington, D.C.: American Society for Microbiology.

Trowsdale, J. \& SMITH, D. A. (1975). Isolation, characterisation and mapping of Bacillus subtilis 168 germination mutants. Journal of Bacteriology 123, 83-95.

VARY, J. C. \& Halvorson, H. O. (1965). Kinetics of germination of Bacillus spores. Journal of Bacteriology 89, 1340-1347.

WoEse, C. R., MoRowitz, H. J. \& Hutchinson, C. A., III (1958). Analysis of action of L-alanine analogues in spore germination. Journal of Bacteriology 76, 578-588. 